\title{
Effect of Smart Goal Setting and Nutritional Assessment on Treatment Compliance in Primary Care Dietetic Treatment
}

\author{
Author(s) \\ Leistra, E.; Streppel, M.T.; Klamer, J.; Tump, A.C.; Weijs, P.J. \\ DOI
}

10.1016/S0261-5614(15)30341-1

\section{Publication date}

2015

Document Version

Submitted manuscript

Published in

Clinical Nutrition

Link to publication

Citation for published version (APA):

Leistra, E., Streppel, M. T., Klamer, J., Tump, A. C., \& Weijs, P. J. (2015). Effect of Smart Goal Setting and Nutritional Assessment on Treatment Compliance in Primary Care Dietetic Treatment. Clinical Nutrition, 34(Supplement 1), S94. https://doi.org/10.1016/S02615614(15)30341-1

If you believe that digital publication of certain material infringes any of your rights or (privacy) interests,

please let the Library know, stating your reasons. In case of a legitimate complaint, the Library will make the material inaccessible and/or remove it from the website. Please contact the library:

https://www.amsterdamuas.com/library/contact/questions, or send a letter to: University Library (Library of the University of Amsterdam and Amsterdam University of Applied Sciences), Secretariat, Singel 425, 1012 WP Amsterdam, The Netherlands. You will be contacted as soon as possible. 


\section{ESPEN 2015 Abstract Submission}

\section{Topic: Nutritional assessment}

Abstract Submission Identifier: ESPEN15-ABS-1362

EFFECT OF SMART GOAL SETTING AND NUTRITIONAL ASSESSMENT ON TREATMENT COMPLIANCE IN PRIMARY CARE DIETETIC TREATMENT

Eva Leistra*1, Martinette T. Streppel ${ }^{1}$, Jolien Klamer ${ }^{1}$, Anita C. Tump ${ }^{1}$, Peter J. Weijs ${ }^{1,2}$

${ }^{1}$ Nutrition and Dietetics, School of Sports and Nutrition, Amsterdam University of Applied Sciences, ${ }^{2}$ Nutrition and Dietetics, Internal Medicine, VU University Medical Center, Amsterdam, Netherlands

If you think another topic than the one selected at first would suit your abstract, please choose below.: Nutritional epidemiology

Presentation Method: Oral or Poster presentation

Please indicate your professional occupation: Other

The presenting author fulfills the above conditions and wants to apply for a travel award: Yes

I confirm that the presenting author is under the age of 35: Yes

Rationale: Primary care dieticians need to demonstrate their effectiveness to both patients and stakeholders. Treatment compliance influences overall treatment effectiveness. We studied the influence of (SMART) goal setting and the use of Nutritional Assessment on treatment compliance after 1 consultation.

Methods: This study was part of the DIEET study (DIEtetics: Effective and Towards a sustainable profession). Trained students performed structured observations during first dietetic consultations in the primary care setting. Primary focus was on SMART goal setting and Nutritional Assessment (measuring weight, height, waist circumference, bioelectrical impedance analysis (BIA)). At 6-month follow-up data were obtained on moment of treatment termination. Univariate logistic regression analysis was used to express associations between goal setting and Nutritional Assessment and treatment compliance after 1 consultation.

Results: Data were obtained from 289 patients (41\% male; $57 \pm 14$ y; primary diagnosis: overweight (44\%), DM2 (37\%), other $(19 \%)) .47$ patients (16\%) had only one dietetic consultation. During first consultation, treatment goals were defined in 199 patients (69\%), SMART goals in 57 (20\%). Nutritional assessment was performed in 230 patients (80\%).

Treatment compliance after 1 consultation was associated with goal setting in general (OR $2.8[95 \% \mathrm{Cl} 1.5-5.3] \mathrm{p}<0.01)$ and SMART goal setting (OR $3.0[95 \% \mathrm{Cl} 1.0-8.8] \mathrm{p}=0.03)$, and performing Nutritional Assessment $(\mathrm{OR} 2.4[95 \% \mathrm{Cl} 1.2-$ 4.8] $\mathrm{p}=0.01$ ).

Conclusion: Setting SMART treatment goals and performing Nutritional Assessment during first dietetic consultations are related to higher treatment compliance in primary care setting. The DIEET study will further explore whether SMART goal setting and performing Nutritional Assessment during the first consultation will result in higher long-term effectiveness.

Disclosure of Interest: None Declared

Keywords: SMART goal setting, treatment compliance 